\title{
Towards decolonising teaching strategies: How to domesticate and infuse Western science with indigenous knowledge
}

\section{Oscar Koopman}

Senior Phase - Further Education and Training Department, Faculty of Education, Cape Peninsula University of Technology, Mowbray, South Africa

KoopmanO@cput.ac.za

http://orchid.org/ 0000-0002-1508-3967

(Received: 26 April 2018; accepted: 8 November 2018)

\section{Abstract}

Through recent violent protests, university students across South Africa have demanded a decolonised curriculum that includes incorporating indigenous knowledge into it. In response to that demand I pursue three aims in this article. First, I examine why it is important to infuse both indigenous knowledge and Western science into the school science curriculum. Second, I discuss Jegede's collateral learning theory and Piaget's theories relating to cognitive development in order to explain not only how African learners learn science but, more specifically, the cognitive challenges they might face when the focus is only on Western knowledge. Third, I recommend some teaching approaches on how to domesticate and infuse Western science with indigenous knowledge in the science classroom. Accordingly, I present practical examples of the ways in which teachers can teach both bodies of knowledge to make science more meaningful and appropriate to most African learners. I want to stimulate thinking about the importance of indigenous knowledge in school science today, as well as consider the implications for a shift in teacher pedagogy that a decolonial curriculum requires.

Keywords: decolonisation, Western science, Indigenous knowledge; science; teaching strategies

\section{Introduction}

What started out as a war against statues in universities and across South Africa in 2015 coalesced into a demand for free higher education and the decolonisation of the university in 2016. Subsequently, the nationwide student protests towards the end of 2015 and in 2016 led to the president of South Africa, in 2016, publicly announcing free education for the poor, while the minster of higher education made the announcement that the university curriculum must be decolonised. These developments in universities served as an urgent wake-up call for the Department of Basic Education to decolonise school curricula, especially the school science curriculum. African scholars had argued for decades that African children, in their illfated relationship with school science, continued to be caught up in Western frameworks of thinking that caused serious cognitive conflicts (Aikenhead, 1996; Jegede, 1999; le Grange, 
2007, 2008, 2017; Ogunniyi, 2007; Ogunniyi \& Ogawa, 2008). The question that now arises is: What does the phrase decolonising the curriculum mean?

To le Grange (2016), decolonisation meant Africanising the curriculum. Simply put, this entails the inclusion of a body of knowledge that is underpinned by African philosophical thinking and social practices that have evolved over thousands of years. He emphasised the point that Western science should not be discounted or completely removed from the curriculum but infused with indigenous knowledge. Ethieyibo (2016) viewed decolonisation as the "adoption, appropriation and incorporation of salient features or characteristics, experiences, practices, beliefs, values and modes of the African way of life that are representative and distinctive of sub-Saharan black people" (p. 405). This means that the decolonisation project should rupture and challenge the Western ideas and knowledge that dominate school science. Ethieyibo was in agreement with le Grange when he pointed out that instead of following a radical approach to decolonisation - the total exclusion of Western knowledge from the curriculum - a more moderate approach should be adopted; Western and indigenous knowledge should be taught as complementary bodies of knowledge. According to Ogunniyi (2007), if we continue to ignore these African insights, ideas, and values in our school science curricula, we become complicit in epistemic injustice.

Given that the overwhelming majority of South African learners are African, it is essential that school science be presented as a bicultural engagement in which both Western science and indigenous knowledge are fused in order to create equivalences and connections between the two knowledge systems so that learners can negotiate new personal meanings. This raises the question that is also my main focus in this paper: How can the suggestions for the inclusion of indigenous knowledge into the school science curriculum be realised at the classroom interface? If the aim is to adopt a moderate approach to decolonisation, another equally important question arises: How can science teachers domesticate Western science in their classrooms? The term domesticate, as Wiredu (2005) noted, means to present knowledge that is foreign to a person in ways that take into account the lived realities of that person. He has argued for the harmonisation of Western individualism with African traditional communalism. According to Waghid (2014), domestication here refers to using African thinking and ways of life as a basis from which to introduce Western knowledge. In the context of this paper, domestication of Western science means that teachers should deconstruct Western ideas and present them to their learners in ways that are directly linked to their everyday lived realities in order to make science more meaningful, appropriate, and relevant in every way to school children.

\section{Why are both Western science and indigenous knowledge important to school science?}

Here I point out, first, why it is important to incorporate both indigenous knowledge and Western science into the school science curriculum. Second, drawing on Jegede's (1999) collateral learning theory and Piaget's (1954) cognitive learning theory, I discuss how African learners learn science, and consider the cognitive challenges they face when the focus 
is only on Western knowledge. Third, I suggest effective teaching approaches that will give due recognition to both Western and indigenous knowledge and will fuse these knowledges. To do this, I present practical examples of how teachers can teach both bodies of knowledge to make science more meaningful and appropriate to most African learners. Before I do this, though, I must shift the discussion to a consideration of why both Western and indigenous knowledges are important in the science classroom.

Niezen (2003) explained how indigeneity emerged as such a salient feature in the aftermath of colonialism and genocide when he wrote that "indigeneity is an identity, like that which unifies survivors of the Holocaust, grounded in evidence, testimony and collective evidence" (p.15). Simon (2010) noted that each indigenous community has its own history of colonialism, resistance, and agency. In Africa the term indigenous people is seldom used and is more often replaced with terms such as tribes or ethnic groups (Eversole, 2005). Shizha (2008) described indigenous people in Africa as all African citizens who are African not through being the offspring of settlers or colonisers. His view is that these indigenous people have a long history of African ancestry and identify with many rural communities. It is in these cultural lifestyles embedded in authentic spiritual, ecological, and holistic economic and political experiences that indigenous knowledge has its roots. Gratton (2003) echoed the notion that a unique philosophy drives indigenous communities and provides an indigenous intellectual matrix to the respective groups. According to Oruka (1990), in each indigenous community sages (wise men and women) play a critical role in establishing these intellectual matrices as they critically evaluate what might be considered acceptable ways of understanding the world. These acceptable ways are what give rise to indigenous knowledge among local communities. Battiste, thus, defined indigenous knowledge as the "vibrant relationships between the people, their ecosystems, and the other living beings and spirits that share their lands" (as cited in Battiste \& Henderson, 2000, p. 42). Ogunniyi and Ogawa (2008) explained the term in much more detail.

The term indigenous knowledge stands for an idea or system of thought peculiar to the so-called natives of a particular geographical location or socio-cultural environment. This implies that the knowledge has not been borrowed from another locality or culture or, if borrowed, it has become so assimilated into the new culture that it is difficult if not impossible to identify its original character or foreignness. (p. 177)

Dei, Hall, and Rosenberg (2000), in agreement with the above view, stated that the focus of this knowledge is on traditional norms and social values as well as on the mental constructs that guide, organise, and regulate people's lifeworld. Ellen, Parkes, and Bicker (2000) noted three elements in indigenous knowledge: (i) the outcome of a dynamic system, which they refer to as the innovative talents of each indigenous person; (ii) an indispensable part of the physical and social environment of the community; and (iii) collective well-being. All these elements form a system of thought and ideas that are anthropomorphic, monistic, and metaphysical in nature. Furthermore, they are local or specific to a particular place. This 
knowledge is informed by a latent worldview that drives the everyday actions and behaviour of many African people.

What separates indigenous knowledge from knowledge in the Western tradition is that the former excludes colonial and imperial impositions. As I have argued elsewhere (Koopman, 2017), in order for knowledge to be classified as valid Western knowledge, it must be (i) empirically verifiable, (ii) conform to ontological principles, theories, and laws, and (iii) be experientially consistent. Therefore, based on the fact that science is driven by the principles of empiricism, quantification, reductionism, and anthropocentricism (Ogunniyi \& Ogawa, 2008), it shares common features with indigenous knowledge such as logic, common sense, creativity, place, and, in some cases, serendipity. Ogunniyi and Ogawa (2008) have explained the connectedness of the two knowledge types by looking at how modern medicine and indigenous knowledge have complemented each other for decades. They explained how hundreds of medicinal plant species have been studied for their use as therapeutic agents and/or their dietary properties. Furthermore, there is consensus in the literature that both Western science and indigenous knowledge are in search of arriving at an understanding of human experiences in relation to nature and of the knowledge necessary to live a normal life. Aikenhead (1996) pointed out that both these knowledge types are governed by borders that are very porous given that people often find themselves in between the two systems, the borders of which can be crossed with relative ease, depending on how embedded a person is in a particular worldview. However, when it comes to formal spaces of learning, indigenous knowledge is often globally viewed as inadequate and inferior to Western traditions and, therefore, it is argued in the literature that it should not form part of school science curricula.

Many science education scholars, such as Aikenhead (1996), Jegede (1999), Kapoor and Shizha (2010), as well as Ogunniyi and Ogawa (2008) have disagreed with this view and argued that a solution to the main challenges-such as poverty, economic marginalisation, hazardous health conditions, and poor education-facing the African continent lie in the design and development of programmes that recognise that indigenous knowledge is the bedrock of the African psyche and way of life. While these scholars have argued for an indigenised curriculum, le Grange (2008) and Waghid (2014) have advocated for a marriage between the two knowledge traditions as a way of domesticating knowledge. Le Grange (2008), on his part, has argued that the fusion of Western science and indigenous knowledge could take us to new knowledge spaces that could have transformative effects for South Africa's science programmes. He supported this argument by explaining how the Aborigines in Northern Australia domesticated Western knowledge and ideas by mapping every tree and significant terrain using digital satellite technology and made this available through geographical information systems to the West. Waghid (2014), in agreement with le Grange (2008), has cautioned us that education in South Africa should not be only about invoking the African voice, values, and identity because this would create the idea that there is a single, homogenous, and monolithic African culture and identity. Instead of polarising Western and indigenous ideas, he argued, Western knowledge should be considered as a complementary body of knowledge. He explained this idea by pointing out that a medical cure for HIV and AIDS should not rely solely on traditional herbal remedies prescribed by local traditional 
healers. So, instead of rejecting Western solutions to the HIV and AIDS pandemic, people can use both antiretroviral and herbal remedies to treat sufferers. Marginalising Western knowledge and ideas means discounting rich contributions from knowledge developed elsewhere. Another reason why both bodies of knowledge are important in the science classroom is that most teachers in South Africa - unlike those who lived in rural villages and who have their roots and cultural experiences in indigenous communities-received their training at school and university level in the tradition of Western science and, therefore, most teachers need first to be trained in the traditions of indigenous knowledge.

\section{How African learners learn science}

According to Piaget (1954), the cognitive development of a child is centred on the child's mental processes such as perceiving, remembering, believing, and reasoning. These mental computations are directly dependent on the child's experiences in the real world through doing and acting in it. In other words, the world is not just observed and imitated by the child, but also interpreted. While Piaget's theory looked at cognitive development among children in general, Jegede's (1999) collateral theory is specific to science and explained how a child copes cognitively when introduced to hostile learning environments-such as African learners being introduced to Western science. Because of the resilience of African learners' cultural frameworks, it is important to understand their cognitive development (from the perspective of both Piaget's and Jegede's frameworks of learning) in order to become aware of their different ways of coping when they are introduced to school science, and how a duality of thought in their memory and schemata arises.

Jegede (1999) identified four different types of collateral learning-parallel, simultaneous, dependent, and secure - that take place in the science classroom when an African learner is confronted with Western science. According to Piaget (1954), each of these different types of learning can lead to different ways of understanding and cognitive assimilation, depending on the child's continuous organisation and reorganisation of information through experience. In the light of this, le Grange (2007) has stated that these four different types of collateral learning should not be viewed as discrete or existing in isolation from one another but must be viewed as occurring on a continuum over time because one type can lead to the next.

According to Jegede (1999), parallel collateral learning takes place when the learner holds two conflicting or opposing ideas side by side at the same time. This means the learner stores both the scientific knowledge and the indigenous or cultural knowledge in his or her longterm memory at the same time with minimal interference and interaction. This is evident in learners who are introduced to school science for the first time. According to Piaget (1954), the mental structures of children at an early age are still underdeveloped. These mental structures, which are made up of the motor and sensory modalities, limit very young children's mental functioning. As they become older, they learn how to (re)construct these sensory modalities to deal with their environments or, in this case, with the learning material. In other words, the learning of new ideas grows out of a child's processing and understanding of prior ideas (Piaget, 1954). According to Singer and Revenson (1996), the child in the 
science classroom, during parallel collateral learning, experiences what Piaget referred to as adaptation, which he described as the most basic principle of human functioning. These authors aver that adaptation takes place when the child processes information by using his or her environment or experiences as a primer to adjust his or her cognitive processes. Further cognitive dissonance arises for a child when the learning material with which the child is confronted is not domesticated in order to make science more meaningful and appropriate to the lived realities of the child. Instead, the science presented to the child is beyond the child's indigenous outlook on the world.

The second type of collateral learning is simultaneous collateral learning. This process takes place over a longer period of time than does parallel collateral learning. This is because by the time learners are introduced to the new scientific information, they might still be processing a concept they learned at home or in their cultural setting. This means the learner has to resolve the tension between the two concepts at the same time because both are new to his or her cosmos (Jegede, 1999). This process within which a child is confronted with two opposing worldviews, Piaget (1954) called assimilation. He described assimilation as the process in which the child takes in new information and fits it into a preconceived notion or idea about the world (Singer \& Revenson, 1996). During this process, the child incorporates the new Western idea into his or her cognitive framework and remembers it for future use. The way the learner resolves this tension between the two different worldviews (Western and indigenous) depends on the fruitfulness and plausibility of the knowledge for the child; this leads to the third type of collateral learning.

The third type is dependent collateral learning. This takes place when the schema from the Western scientific worldview challenges the child's cultural or indigenous worldview, enabling the learner to restructure or modify his or her existing schemata. The shift to the new schemata is triggered by what the learner already knows. This means the learner can make a shift in favour of, or against, the cultural worldview-depending on what already exists in his or her mind. Piaget (1954) referred to this process as accommodation. During this (accommodation) process, the child attempts to understand Western science by applying the prevailing cultural framework or an old experience (assimilation). If this does not work, the child is forced to change his or her existing conception in order to interpret the new knowledge or idea. This stage of cognitive development can also be described as a dual process, namely the assimilation-accommodation process.

The fourth and last type of collateral learning is secured collateral learning. Jegede (1999) argued that this type of collateral learning takes place over a long period of time in which the learner must resolve the tension between the two opposing knowledge frameworks. This means that the learner must resolve what he, Jegede, terms cognitive dissonance in the knowledge base of the embedded long-term memory. This cognitive dissonance represents the conflicting worldviews implicit in the Western science with which the learner is confronted in the science classroom, and in the cultural knowledge he or she brings to the classroom. To resolve the conflict, Jegede (1999) argued, the learner draws from a "convergence towards commonality" (p. 135) that secures the newly acculturated conception. 
This acculturated conception is what Piaget (1954) referred to as the construction or formation of the schema through a process of adaptation. He explained that a schema is a simple mental image or "pattern of action, a form of organizing information that a person uses to interpret the things she sees, hears, smells and touches" (cited in Singer \& Revenson, 1996, p. 17). A schema organises perceptions, ideas, and understanding of the world the way a computer organises its files and documents. When necessary, the child can retrieve the information stored in his or her memory to solve a scientific problem. This process of cognitive accommodation can take place more smoothly if the teacher can domesticate the Western ideas by linking them to the child's lived experience.

While Jegede's (1999) collateral learning theory explains how the learner copes with different experiences in the science classroom, Piaget's (1954) view of cognitive development explains the intellectual processes that takes place in the mind of the child when introduced to Western science. These theories remind science teachers of the importance of domesticating Western knowledge and ideas when introducing them to African learners. During transitional periods, the child might be in one of the four stages regarding his or her understanding of school science. These stages are not directly related to specific age groups and can vary widely. What is of greatest significance is that before teachers introduce their learners to abstract scientific concepts, it is important that they first help learners understand the concrete scientific terms and ideas.

\section{Personal-Cultural-Localised Learning (PCLL)}

Given the overwhelming evidence in the literature that points to poor science teaching, and the cry for decolonisation in South African classrooms and lecture theatres, there appears to be a paucity of effective pedagogical strategies to facilitate curriculum change. According to Ogunniyi (2007), despite concerted efforts by the new government in South Africa to encourage teachers to incorporate indigenous knowledge in their science classrooms, teachers continue to dismiss indigenous ways of knowing because (i) they were trained in the tradition of Western science and are not familiar with the precepts of indigenous science and (ii) teachers resist changes to their pedagogical strategies in terms of contextualisation and indigenisation. Therefore, instead of complementing Western modern science with indigenous, as prescribed in CAPS and all its predecessor curricula such as OBE, NCS, and so forth (see DBE, 2011), science teachers place more emphasis on Western science because of the pressure to achieve high test scores and good examination results.

One approach that I want to introduce here has been adapted from Schmidt, Rosenberg, and Beymer's (2018) person-oriented approach to learner engagement, in which Western and indigenous knowledge can be fused in what I refer to as personal, cultural and localised learning (PCLL). Personal, in PCLL, refers to the teacher and his or her role in becoming cognisant of the context in which he or she teaches. More specifically, personal lived experiences are part of the experiential knowledge of nature that the child brings into the classroom. According to Fitts and Posner (1967), all knowledge and skills have their roots in people's interactions with the real world. They argued that our minds operate like computers 
processing information from the environment through a series of learnt rules. As a child experiences phenomena and, in the process, learns and develops a skill, he or she learns to refine the rules in order to master the skill. For example, young children might not have a full understanding of gravity, but they are aware that objects in free fall are pulled downwards by some inexplicable force. Another example is the observation that a brick sinks and a ball floats when they are dropped into water. Although children might not have a holistic understanding of density and buoyancy, they do have real experiences of such events.

Cultural and localised knowledge refers to the cultural knowledge acquired in the localised community within which the child resides. According to Aikenhead (1996), in most cases the knowledge the learner holds, from the traditional perspective, comes from the meaning and identity acquired by him or her through the local community's indigenous cultural identity. According to Wallace (2004), when a teacher becomes aware of the cultural understandings of the learners, he or she moves away from the privileged authoritative discourse and dominance of school science and provides indigenous learners with improved access to Westernised science. This allows the teacher to domesticate and fuse the knowledge systems by first embracing and validating local people's own ways of understanding, while also allowing the teacher space to negotiate new meanings that can possibly resolve the dichotomy of dual thought. One of the drawbacks of this approach is that gathering such alternative views embedded in a cultural discourse is time consuming and limits the teacher's contact time with the learners. However, a plethora of alternative approaches may be found in the literature. For example, by networking with the research community and experts in indigenous knowledge, teachers can gather (or survey) and become aware of many localised ideas and knowledge. These ideas and worldviews can be shared in their respective clusters from district offices. This raises the question: How can teachers apply PCLL in their classrooms?

Once the teacher has gathered or collected personalised experiences and cultural understandings from the learners, when introducing a topic or concept, for example, such as lightning as a form of static electricity, it is important that the teacher has a good understanding of the African concept of umbane. This concept of umbane illustrates the destructive capacity of a sangoma who is believed to have supernatural powers. This means that a sangoma has the power to generate and direct lightning to a particular house, which can have serious destructive consequences. Hence, lightning in African traditions is not a natural phenomenon but a form of witchcraft that indicates that a person has angered the ancestors. In the Western tradition, lightning has a completely different meaning; it is explained scientifically as occurring or taking place when lighter subatomic particles in a cloud move towards the upper part of the cloud, which becomes positively charged in the process. Heavier subatomic particles in the clouds move towards the bottom and become negatively charged. When the positive and negative charges become large enough, lightning is released between these regions. Most of the lightning takes place between the clouds, but some is discharged and strikes the earth in bright flashes. These bright flashes are the discharge of electrons, which have the potential to kill or injure animals or humans on the ground because they contain thousands of volts that are released in a fraction of a second. 
In other words, the role of the teacher in this instance is to adopt that of what le Grange (2008) called a cultural broker before invoking a Westernised explanation. If a teacher ignores the cultural profile of the child, this creates what Jegede (1999) referred to as collateral learning (as explained above) and, to bypass this dual conceptual notion, it is important to invite epistemological dialogue about such phenomena. This inter-

epistemological dialogue allows the learner to negotiate meaning between the indigenous and Western knowledges in order to create new knowledge spaces in which alternative views and ideas are shared among learners coming from different cultures. Once teachers develop a robust understanding of personalised or cultural data on various concepts, they can document them in order to design teaching approaches and strategies that they can use to domesticate complex and abstract scientific concepts and fuse the two knowledge traditions. By doing so, learning science becomes a two-way flow and no longer a unidirectional pathway of science teaching focusing only on Western ideas and explanations. Therefore, instead of just going through the motions of teaching science through hands-on activities and what we might call talking science, learners see the wonder and beauty of both indigenous knowledge and Western science as an integrated body of knowledge. Discounting indigenous knowledge is one of the main challenges that can make learners unresponsive to the learning of Western science (Aikenhead, 1996), with its abstract, complex language and terminology with which learners struggle to connect. Acknowledging and merging the personal knowledge and cultural worldviews of learners with Western terminology and ideas could result in better understandings of science.

Another outcome that could result from the inter-epistemological dialogue of fusing the two knowledge types is the development of a more learner-friendly language through which science can be presented. This means that science teachers and local communities will have to collaborate in order to develop an indigenous vocabulary for science in the local languages; this is one way of resolving the tension between indigenous knowledge and Western knowledge. Translating Western scientific precepts into local languages creates multiple discourses and forms of dialogue that will promote greater interest in the scientific description of nature.

When teachers have documented personalised ideas and cultural data, they can shift the focus to group work, which can then be made more interesting not only by focusing on the theoretical dimension, but also in providing learners with activities that involve data analysis and representation that they can discuss in their groups.

I turn, now, to focus on process-oriented guided inquiry learning (POGIL) as an extension of PCLL to suggest a method for the delivery of scientific knowledge through group work.

\section{Process-Oriented Guided Inquiry Learning (POGIL)}

According to Treagust et al. (2018), process-oriented guided inquiry learning (POGIL) is one way to address the superficial engagement of learners with science in bridging the Western and indigenous cultural divide. This strategy has its roots in the Western tradition and has been used in schools in the Middle East to bridge the cultural-theory divide. While PCLL 
focuses on the subjective epistemological experiences of individual learners in their respective communities, POGIL promotes group work as a learner-centred pedagogical approach in which both the practical and theoretical aspects of science are considered. Teaching within a POGIL paradigm, as Spencer and Moog (2008) have noted, requires the teacher to take on the role of a facilitator in which learning becomes a guided experience through group work. What is important in POGIL is that learners are introduced to both the theoretical as well as the empirical aspects of science. This is done by allowing them to explore concepts by examining data or information that is provided by the teacher, and which is set up in such a way that the learner experiences cognitive dissonance. Learners in the groups have different roles to play-leader, recorder, presenter, reflector, or strategy analyst - as well as other roles such as those of technician, encourager, and significant figure checker. All these roles and their respective activities allow them to be introduced to the cultural context of their peers, while at the same time allowing them to get to know the world of the other and how it relates to science. The following scenario serves as an example of a classroom activity aimed at fostering POGIL.

Traditional medicine remains an important option in South Africa. The challenge remains that, as Africans become more educated, they seem to feel that herbal remedies are more primitive and have lost their place or function in society. This is partly because traditional practices are not documented in books and journals but are passed on to a family member through observation, engaging participation, and active listening.

Aphiwe was admitted to hospital and diagnosed with malaria. The following herbal remedies were prescribed or advised to treat the disease: Caesalpina volkensii, Strychnoshenningsii, Ajuga remota, and so forth. All these herbs can be described as antimalarial herbal remedies. However, the chief doctor at Hospital X, where Aphiwe has been admitted, Dr Sibya, feels that Aphiwe should be treated with broad spectrum antibiotics. He also feels that it is irresponsible to entrust the life of a person to a traditional healer who did not formally study medicine. Doing so, he feels, means we are moving back to ancient times.

(i) Suppose Aphiwe is your son. Critically discuss in your groups what you think of Dr Sibya's comment that it is irresponsible to trust a traditional healer.

(ii) In your groups, prepare a 10-minute presentation on who you think should treat Aphiwe. Your presentation must include research evidence on these herbal remedies and anti-malaria antibiotics in support of their success rate or failure in the treatment of malaria.

According to Schmidt et al. (2018), deep engagement with science depends on context, which influences a learner's momentary state while doing an activity. Therefore, it is important that teachers use proximal processes that motivate learners to engage with a particular topic. In other words, some learners might have a deep interest in discovering, by themselves, whether indigenous knowledge or Western science is credible, which will motivate them to a deeper 
engagement that involves not only the cognitive or empirical aspects, but also the behavioural, cultural, and affective aspects. When indigenous knowledge is infused with Western science in group work, it has the potential to spark a sense of belonging and to influence a learner's willingness to participate in a particular lesson. Although he or she might experience negative feelings such as boredom and anxiety (about some topics), peers might introduce ideas that will encourage a response, which could then relate to a specific topic.

Scaffolding the learners in their respective groups would, at times, require the teacher to take on the role of what le Grange (2008) called a tour guide. This means that in cases where the learners espouse strong traditional values, it is recommended that the teacher carefully guide the learners away from creating further cognitive conflict and be mindful of the way he or she sets up the group work in relation to the scientific concept being investigated. In cases where the learners are less deeply entrenched in traditional beliefs and values, the teacher is expected to assume the role of a travel agent. While there will always be individual differences among learners within a particular group, learner contribution is important because it adds value to the learning process. The focus of the group should not be on right or wrong answers because some comments and responses might be interesting and enjoyable and could even serve as a form of entertainment to make the lesson more fun.

In all these situations, it is imperative for the teacher to give learners the choice to select their own groups given that some might share common personal experiences while others might have cultural values in common. Thus, choice can help them relate to the content they are taught in a tangible and meaningful way by helping to shape knowledge construction and scientific reasoning. This will also create a more engaging classroom environment in which both the teacher and the learners in their respective groups are actively involved in the sensemaking process. In such a paradigm, teaching and learning will make more sense to learners because the teacher draws from learners' lived world and cultural experiences; this will make it more probable that they will be able to accommodate the new knowledge as a preamble to understanding Western traditions. Freudenthal (1991) pointed out that we should see science as a human activity and that, consequently, science teachers should guide students to scientificalise their world instead of trying to transfer scientific knowledge as a ready-made product. He alluded to the important role of teachers in guiding their learners in a pedagogy of engagement and nurturing them to participate in the knowledge-construction process.

\section{Conclusion}

Understanding a learner's personalised and cultural worldviews can help teachers to identify the various barriers to learning with respect to understanding certain scientific concepts and definitions. Both personalised and cultural knowledge can be extremely valuable for teachers in the planning and sequencing of events when they deliver their lessons. Therefore, when teachers document personalised and cultural knowledge and ideas that are inconsistent with Western notions of scientific understanding, they should develop and design learning activities that, first, domesticate complex and abstract Western ideas and fuse both bodies of 
knowledge. I argue that an attempt to fuse indigenous knowledge and Western science will, most likely, encourage learner participation either through individualised instruction as discussed in PCCL, or in groups as discussed in POGIL. These two teaching strategies encourage rational engagement and meaning-making in which the learners are introduced to instruction by being offered the chance to uphold traditional beliefs and cross the border to the modern Westernised scientific worldview. These two strategies are consistent with the work of various science education scholars such as Jegede (1999), le Grange (2008, 2017), Ogunniyi (2007), and various others who have proposed that learning activities in the science classroom should be framed in such a way that they develop deep scientific engagement in the learners. Providing learners with the opportunity to solve problems by using their past experiences and cultural knowledge is a step in the direction of decolonising the science curriculum. (I do not address the issue of curriculum content because my main objective is to suggest teaching strategies that can be used to implement both Western science and indigenous knowledge as complementary bodies of knowledge.)

The strategies presented in this paper can be used as a basis to generate personalised and local cultural knowledge that teachers can document. These personalised and culturally local ideas and notions generated in PCCL and POGIL could serve as the basis for developing an indigenised or localised cultural perspective on scientific phenomena. These phenomena can then be exchanged in the respective clusters to develop a formal school science curriculum that values the various alternative conceptions that can, in turn, be used as a basis to introduce new concepts and topics in science. It is important to update such knowledge regularly given that knowledge is not stationary but always shifting to incorporate new ways of understanding the world.

\section{Acknowledgements}

I would like to thank the anonymous reviewers for their constructive feedback in strengthening the academic quality of this article. I would also like to thank the National Research Foundation, grant number TTK160504163990, for their financial support.

\section{References}

Aikenhead, G. (1996). Science education: Border crossing into the sub-culture of science. Studies in Science Education, 27(1), 1-57.

Battiste, M., \& Henderson, J. (2000). Protecting indigenous knowledge and heritage: A global challenge. Saskatoon, CA: Purich.

Dei, G., Hall, B., \& Rosenberg, D. (Eds.). (2000). Indigenous knowledges in global contexts: Multiple readings of our world. Toronto, CA: University of Toronto Press.

Department of Basic Education. (2011). Curriculum and assessment policy statement for the further education and training phase for physical science. Pretoria, RSA: Department of Basic Education. 
Ellen, R., Parkes, P., \& Bicker, A. (2000). Indigenous environmental knowledge and its transformation: Critical anthropological perspectives. New York, NY: Routledge.

Ethieyibo, E. (2016). Why ought the philosophy curriculum in universities in Africa be Africanised? South African Journal of Philosophy, 35(4), 404-417.

Eversole, R. (2005). Overview: Patterns of indigenous disadvantage worldwide. In R. Eversole, J. McNeish, \& A. Cimadamore (Eds.), Indigenous peoples and poverty: An international perspective (pp. 29-37). London, UK: Zed Books.

Fitts, P., \& Posner, M. (1967). Human performance. Belmont, CA: Brooks/Cole.

Freudenthal, H. (1991). Revisiting mathematics education. Dordrecht, NL: Kluwer.

Gratton, P. (2003). What's in a name? African philosophy in the making. Philosophia Africana, 6(2), 61-80.

Jegede, O. (1999). Science education in nonwestern cultures: Towards a theory of collateral learning. In L. Semali \& J. Kincheloe (Eds.), What is indigenous knowledge? Voices from the academy (pp. 119-142). New York, NY: Falmer Press.

Kapoor, D., \& Shizha, E. (2010). Indigenous knowledge in Asia/Pacific and Africa. New York, NY: Palgrave Macmillan.

Koopman, O. (2017). Science education and curriculum in South Africa. New York, NY: Palgrave MacMillan.

le Grange, L. (2007). Integrating Western and indigenous knowledge systems: The basis for effective science education in South Africa. International Review of Education, 53(5), $577-591$.

le Grange, L. (2008). Challenges for enacting an indigenised curriculum: A reply to Ogunniyi and Ogawa. South African Journal of Higher Education, 22(1), 817-826.

le Grange, L. (2016). Decolonising the university curriculum. South African Journal of Higher Education, 30(2), 1-12.

le Grange, L. (2017). Rethinking learner-centredness in science and mathematics education: A conceptual exploration (Unpublished paper). Stellenbosch University, Stellenbosch, RSA.

Niezen, R. (2003). The origins of indigenism: Human rights and the politics of identity. Berkeley, CA: University of California Press.

Ogunniyi, M. B. (2007). Teachers' stances and practical argument regarding a scienceindigenous knowledge curriculum: Part 1. International Journal of Science Education, 29(8), 963-986. 
Ogunniyi, M. B., \& Ogawa, M. (2008). The prospects and challenges of training South African and Japanese educators to enact an indigenised science curriculum. South African Journal of Higher Education, 22(1), 175-190.

Oruka, H. (1990). Sage philosophy. New York, NY: Brill.

Piaget, J. (1954). The construction of reality in the child. New York, NY: Routledge

Schmidt, J. A., Rosenberg, J. M., \& Beymer, P. N. (2018). A person-in-context approach to student engagement in science: Examining learning activities and choice. Journal of Research in Science Teaching, 55(1), 19-43.

Shizha, E. (2008). Globalization and indigenous knowledge: An African postcolonial theoretical analysis. In A. A. Abdi \& S. Guo (Eds.), Education and social development: Global issues and analysis (pp. 37-56). Rotterdam, NL: Sense.

Simon, S. (2010). Animals, ghosts and ancestors: Traditional knowledge of Truku hunters and Formosa. In D. Kapoor \& E. Shizha (Eds). Indigenous knowledge and learning in Asia/Pacific and Africa (pp. 81-95). New York: Palgrave MacMillan.

Singer, D. J., \& Revenson, T. A. S. (1996). A Piaget primer: How a child thinks. New York, NY: Plum.

Spencer, K. N., \& Moog, R. S. (2008). POGIL in the chemistry classroom. In R. S Moog \& J. N Spencer (Eds.), Process orientated inquiry learning (pp. 148-156). Washington DC: American Chemical Society.

Treagust, D. F., Qureshi, S. S., Vishnumolakala, V. R., Ojeil, J., Mocerino, M., \& Southan, D. (2018). Process-oriented guided inquiry learning as a culturally relevant pedagogy in Qatar: A perspective from Grade 10 chemistry classes. Research in Science Education 1-19. Retrieved from Res Sci Educ https://doi.org/10.1007/s11165-0189712-0

Waghid, Y. (2014). Towards an African philosophy of education. New York, NY: Routledge.

Wallace, C. S. (2004). Framing new research in science literacy and language use:

Authenticity, multiple discourses and the 'third space'. Science Education, 88, 901914.

Wiredu, K. (2005). Philosophical considerations on the Africanisation of higher education. In Y. Waghid, B. van Wyk, F. Adams, \& I. November (Eds.), African(a) philosophy of education: Reconstructions and deconstructions (pp. 6-18). Stellenbosch, RSA: Stellenbosch University Press. 